\title{
A DOUBLE-BLIND, PLACEBO-CONTROLLED STUDY OF THE EFFECT OF IMIPRAMINE ON TRH-INDUCED URINARY URGENCY IN HEALTHY MEN
}

\author{
NORMAN E. Alessi ${ }^{1}$, Christopher D. KNIGHT ${ }^{1}$, JOSEPH T. Bergs ${ }^{2}$, and SuSAN J. EISNER ${ }^{1}$ \\ ${ }^{1}$ University of Michigan Medical Center, Child and Adolescent Psychiatric Hospital, Ann Arbor, Michigan, and \\ ${ }^{2}$ Psychiatric Center of Racine, Racine, Wisconsin, U.S.A.
}

(Received 8 August 1990; in final form 14 August 1991)

\section{SUMMARY}

\begin{abstract}
We studied the effect of imipramine (IMI) on thyroid releasing hormone (TRH)-induced urinary urgency as a way of investigating the mechanism of the beneficial effect of IMI on enuresis. In a double-blind study, 12 normal, healthy men between 21 and $39 \mathrm{yr}$ of age ranked their urge to urinate at 30-sec intervals following IV injection of TRH $(500 \mu \mathrm{g})$ or saline. The subjects then were randomly assigned to either IMI $(1 \mathrm{mg} / \mathrm{kg})$ or placebo groups for 10 days, and the procedure was repeated. Compared to saline, TRH produced a significant elevation in urinary urgency in all subjects. IMI did not significantly blunt TRH-induced urinary urgency. Thus, the mechanism by which IMI affects enuresis is likely not mediated at the level of the urinary urgency induced by TRH.
\end{abstract}

\section{INTRODUCTION}

Enuresis is a common childhood problem affecting from $14 \%$ of children at age 5 yr to $1 \%-2 \%$ of children at $14 \mathrm{yr}$ of age (Shaffer, 1985). Among various purported therapeutic interventions, tricyclic antidepressants (TCA) are the single class of medications which have been demonstrated to be effective in controlling enuresis. Approximately $50 \%-60 \%$ of children taking imipramine (IMI), a common TCA, will have at least a 50\% reduction of wetting frequency (Bindeglas et al., 1968) usually within the first week of use (Rapoport et al., 1980). The effectiveness of IMI does not seem to be related to its antidepressant effect, because it is equally useful for children with and without psychiatric disorders, and the onset of its effectiveness occurs within 7 days, vs. up to 14 days for its antidepressant effect (Shaffer et al., 1968).

The mechanism by which TCAs work in controlling enuresis has been studied but is still not understood. It does not seem to be related to changes in sleep architecture (Mikkelsen $e t$ al., 1980), and it is not related to the tricyclics' antiadrenergic or anticholinergic properties, since primary anticholinergic and antiadrenergic agents have not been useful (Wallace \& Forsythe, 1969; Shaffer et al., 1978). However, it has been shown that, with chronic administration, TCAs increase bladder pressure and decrease bladder compliance, resulting in a measurable increase in functional bladder capacity (Hagglund \& Parkkulainen, 1965; Esperanca \& Gerrard, 1969; Vaidyanathan et al., 1983).

Address correspondence and reprint requests to: Dr. N. E. Alessi, Child and Adolescent Psychiatric Hospital, University of Michigan, 200 East Hospital Drive, Ann Arbor MI 48109-0290, USA. 
Several studies have linked the hypothalamo-pituitary-thyroid (HPT) axis with the urinary tract and may provide insight into the mechanism by which IMI effects enuresis. Nathan (1983) observed that $95 \%$ of patients who received $500 \mu \mathrm{g}$ TRH IV experienced urinary urgency. Bhatia and Bergman (1988) noted that urinary urgency occurred in $80 \%$ of female subjects and correlated with changes in urethral closure pressure when TRH was administered during urethrocystometry. However, after bolus injections of TRH, there were no changes noted in bladder pressure. Furthermore, a significant percentage (20-33\%) of enuretic children experience an increase in urinary urgency and frequency compared to normal, nonenuretic children (Hallgren, 1956). In adults who continue to be enuretic, the percentage with an increase in frequency and urgency rises to over $60 \%$ (Torrens \& Collins, 1975). Of importance, the only clear finding across the several modes of treatment for enuresis is an increased bladder capacity and decreased frequency and urgency (Starfield \& Mellits, 1968).

The following study was conducted to determine if TRH-induced urinary urgency would be effected by a TCA, IMI, thereby providing a means to better understand both the mechanism of action of the TCA in the treatment of enuresis and the pathophysiology of enuresis.

\section{SUBJECTS AND METHODS}

\section{Subjects}

Twelve men between the ages of 21 and $39 \mathrm{yr}$ were screened for a history of alcoholism, thyroid disease, depression and medication use, including aspirin, barbiturates and lithium. A medical history, psychiatric screen (SADS-L) (Spitzer \& Endicott, 1975), and basic lab tests (total blood survey, urinary analysis, electrocardiogram, and blood chemistry tests) were obtained to document the volunteers' health status. In addition, a toxicology screen was performed for benzodiazepines, cannabinoids, cocaine metabolites, and opiates. The study was approved by the Human Use Institutional Review Board of the University of Michigan before its implementation, and the Code of Ethics of the World Medical Association was observed. All subjects signed a consent form prior to their involvement in the study. Following the completion of the screening, subjects were assigned to either a placebo or an IMI group for the remainder of the study. The groups did not differ significantly by age: IMI group, $28.1 \pm 5.2 \mathrm{yr}$ and placebo group, $28.1 \pm 5.1 \mathrm{yr}$ (mean \pm SD).

\section{TRH stimulation procedure}

A single-blind TRH stimulation procedure was carried out prior to the administration of IMI or placebo. Subjects arrived by $0830 \mathrm{~h}$ after fasting overnight. Upon arrival they were asked to void and were seated upright with their legs raised. An indwelling venous catheter was placed, and at $0900 \mathrm{~h}$ they were injected with $0.5 \mathrm{cc}$ of saline solution. Subjects then were asked to fill out a Urinary Urgency Rating Scale (UURS) every $30 \mathrm{sec}$ for $20 \mathrm{~min}$ following the injection. At $5 \mathrm{~min}$ after the injection of the saline, each subject was asked to fill out a rating scale consisting of $10 \mathrm{~cm}$ lines for nausea, fatigue, stomach pain, flushing, dizziness, headache, and anxiety. At $0925 \mathrm{~h}$, a blood draw was taken to assess baseline thyroid function, including $\mathrm{T}_{3}$, $\mathrm{T}_{4}$, and TSH. At $0930 \mathrm{~h}, 500 \mu \mathrm{g}$ of TRH (Relefact TRH, protirelin, Hoechst-Roussel Pharmaceuticals) was administered through the catheter, and the subject was again asked to complete the UURS at 30 -sec intervals for $20 \mathrm{~min}$. Side-effects were assessed $5 \mathrm{~min}$ after the injection of the TRH. Upon completion of the TRH stimulation procedure, $30 \mathrm{~min}$ after the TRH injection, a second blood sample was taken to assess changes in TSH.

\section{TSH Assay}

TSH values were determined by the University of Michigan Hospital's Ligand Assay Lab with the Magic Lite TSH immunoassay procedure (Ciba Corning). Sensitivity for this procedure is $0.02 \mu \mathrm{IU} / \mathrm{ml}$, and values are accurate to $100 \mu \mathrm{IU} / \mathrm{ml}$. The intra-assay percent coefficient of variance (singletons) ranges between $2.9 \%$ and $6.5 \%$, and the inter assay percent coefficient of variance between $4.8 \%$ and $10.4 \%$.

Double-blind, placebo-controlled study

Twelve subjects were randomly divided into two groups: an IMI group $(n=7)$ and a placebo group $(n=5)$. 
An EKG was obtained before starting the IMI and after reaching maximum dosage. The IMI group was given IMI, and their dose was increased ovet a period of 3 days until reaching $1 \mathrm{mg} / \mathrm{kg}$. This dose was chosen due to previous studies that have shown this to be the effective dose in the treatment of enuresis in children (Jorgensen et al., 1980). The placebo group was started on placebo and was otherwise treated in an identical fashion. After 10 days, the subjects returned for a second TRH stimulation test identical to the first. Plasma samples were taken from all subjects to determine plasma levels of IMI, desipramine and IMI + desipramine by an HPLC technique (Johnson et al., 1982).

Urinary Urgency Rating Scale (UURS)

The UURS is a $10 \mathrm{~cm}$ analog scale which allows participants to rate their subjective sensation of urgency between 0 (no sensation) and 10 (an extreme sensation to urinate)

\section{Statistical Analyses}

All statistical analyses were carried out with the Apple Macintosh version of Statview. Statistical significance was set at $p<0.05$.

\section{RESULTS}

TSH responses before and after treatment with IMI or placebo are shown in Table I. Before treatment, subjects within both groups showed a significant elevation in TSH in response to TRH injection. TSH values within the placebo group rose an average of $8.5 \pm 2.4 \mu \mathrm{IU} / \mathrm{ml}, 30$ minutes post injection, while values within the IMI group rose an average $10.7 \pm 6.0 \mu \mathrm{IU} / \mathrm{ml}$. After treatment, TSH values within the placebo group rose an average of $8.0 \pm 2.7 \mu \mathrm{IU} / \mathrm{ml}$, while values within the IMI group changed $8.5 \pm 2.5 \mu \mathrm{IU} / \mathrm{ml}$. There was not a significant alteration in the TSH response to TRH in either group after treatment. Mean $T_{3}, T_{4}$, and TSH values before injection and TSH values after injection were not significantly different between groups before or after treatment with IMI or placebo.

In Fig. 1A, the injection of saline did not produce a noticeable effect on urinary urgency in either group. However, TRH injection produced a transient rise in urinary urgency which peaked at approximately $1 \mathrm{~min}$ post-injection in both groups and returned to baseline in $10 \mathrm{~min}$. Pre-treatment urinary urgency responses to saline and TRH injections between the IMI and the placebo groups were not significantly different. At $1 \mathrm{~min}$ after injection, the TRH urinary urgency response vs. saline response was significantly greater in the IMI group, $(\mathrm{df}=6, t=-3.6$,

TABle I. THYroid STIMULATING HORMONE VALUES (MEAN \pm SD) BEFORE AND AFTER INJECTION OF $500 \mu \mathrm{G}$ TRH IN IMIPRAMINE AND PLACEBO GROUPS PRE- AND POST-TREATMENT

\begin{tabular}{|c|c|c|}
\hline & TSH before Injection $(\mu \mathrm{u} / \mathrm{ml})$ & TSH after Injection $(\mu \mathrm{w} / \mathrm{ml})^{*}$ \\
\hline \multicolumn{3}{|l|}{ Placebo Group } \\
\hline pre-treatment $\mathbf{a}$ & $1.2 \pm 0.4$ & $9.7 \pm 2.7^{e}$ \\
\hline post-treatment $t^{b}$ & $1.3 \pm 0.7$ & $9.3 \pm 3.3$ \\
\hline \multicolumn{3}{|l|}{ Imipramine Group } \\
\hline pre-treatmentc & $1.8 \pm 1.0$ & $12.0 \pm 6.4^{f}$ \\
\hline post-treatment & $1.8 \pm 1.0$ & $11.9 \pm 7.3$ \\
\hline
\end{tabular}


A. IMIPRAMINE AND PLACEBO GROUPS PRE-TREATMENT

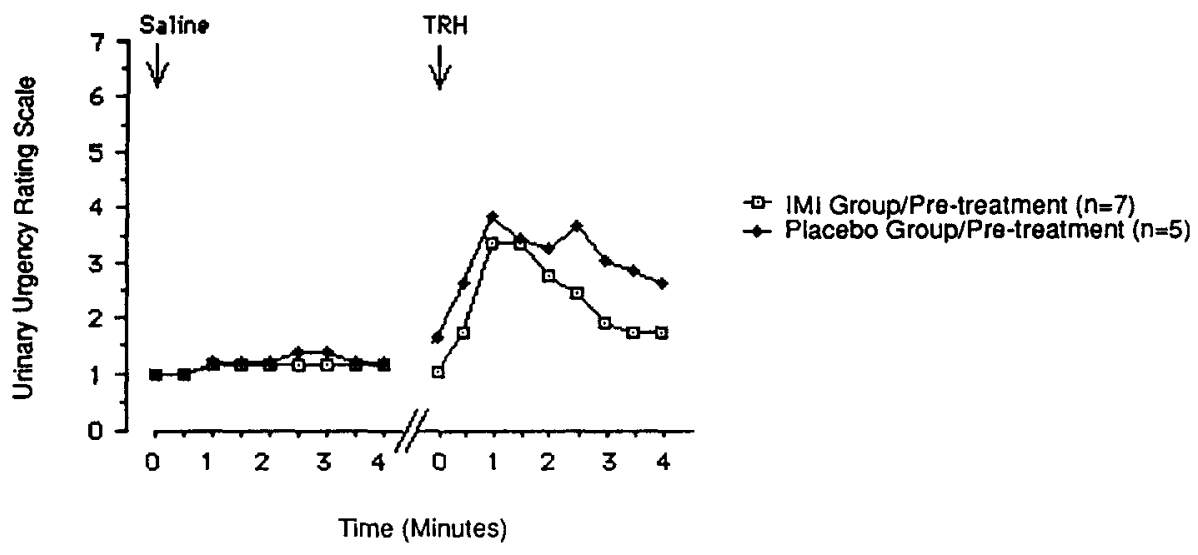

B. IMIPRAMINE AND PLACEBO GROUPS POST-TREATMENT

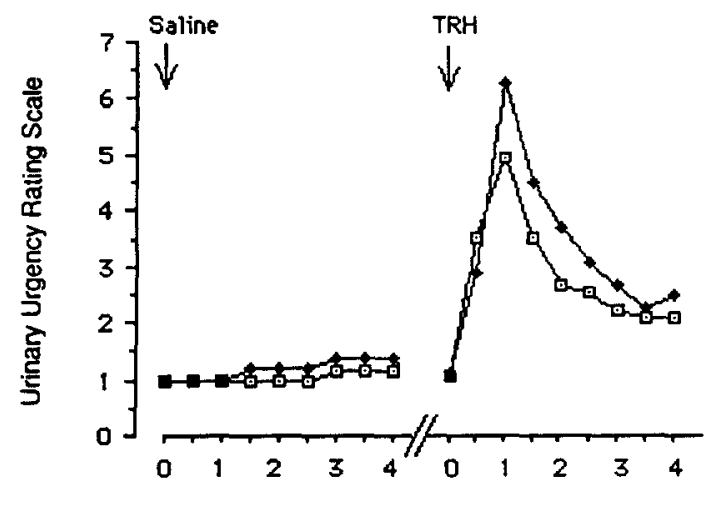

$\rightarrow$ IMI Group/Pre-treatment $(n=7)$ $\leftarrow$ Placebo Group/Pre-treatment $(n=5)$

Time (Minutes)

Measures of urinary urgency: A - placebo vs. imipramine groups, pre-treatment. Comparison of urinary urgency at 1 -min peak: placebo group, $\mathrm{n}=7, \mathrm{df}=4, t=-2.15$, NS; imipramine group, $\mathrm{n}=5, \mathrm{df}=4, t=-3.6$, $p<0.01$. B - placebo vs. imipramine group, post-treatment. Comparison of urinary urgency at 1-min peak, placebo group, $\mathrm{df}=4, t=-6.5, p<0.003$; imipramine group, $\mathrm{df}=6, t=-3.65, p<0.01$.

$p<0.01)$, but not in the placebo group $(\mathrm{df}=4, t=-2.15, p<0.09)$. However, the urinary urgency response to TRH within the placebo group did reach significance within $1 \frac{1}{2} \mathrm{~min}$ post-injection $(\mathrm{df}=4, t=-3.65, p<0.02)$.

Figure 1B shows the urinary urgency response following the administration of IMI or placebo. The response to the saline injection remained the same, with little to no increase. Both groups of patients responded significantly to the administration of TRH compared to the administration of saline at $1 \mathrm{~min}$ after injection (IMI: $\mathrm{df}=6, t=-3.652, p<0.01$; placebo: $\mathrm{df}=4$, $t=-6.5, p<0.003$ ). The IMI treatment group did not demonstrate a significant decrease in urinary urgency compared to that experienced by those receiving placebo. Both groups tended 
TABLE II. NUMBER OF SUbJECTS EXPERIENCING NAUSEA, FATIGUE, STOMACH PAIN, FLUSHING, DIZZINESS, HEADACHE, OR ANXIETY AFTER INJECTION OF $500 \mu \mathrm{G}$ TRH OR SALINE WITHIN IMIPRAMINE AND PLACEBO GROUPS PRE- AND POST-TREATMENT

\begin{tabular}{lcccccccc}
\hline & \multicolumn{3}{c}{ PLACEBO } & \multicolumn{4}{c}{ IMIPRAMINE } \\
& $\begin{array}{l}\text { Pre-Treatment } \\
\text { Saline }\end{array}$ & TRH & Post-Treatment & Pre-Treatment & Post-Treatment \\
& 0 & $4^{\mathrm{a}}$ & 0 & $5^{\mathrm{b}}$ & 1 & $5^{\mathrm{c}}$ & 1 & 4 \\
Nausea & 0 & 1 & 1 & 2 & 0 & 0 & 1 & 1 \\
Fatigue & 0 & 1 & 0 & 2 & 0 & 3 & 0 & 1 \\
Stomach Pain & 1 & 3 & 0 & 3 & 0 & 3 & 1 & 4 \\
Flushing & 2 & 3 & 0 & 2 & 1 & 4 & 0 & 2 \\
Dizziness & 0 & 2 & 0 & 2 & 0 & 2 & 0 & 2 \\
Headache & 0 & 2 & 0 & 1 & 0 & 2 & 0 & 1 \\
Anxiety & 2 & & & & Saline & TRH & Saline & TRH \\
\hline
\end{tabular}

${ }^{a} p<0.05,{ }^{b} p<0.04,{ }^{c} p<0.03$, saline vs. TRH.

TABLE III. NUMBER OF SIDE EFFECTS EXPERIENCED BY SUBJECTS AFTER INJECTION OF $500 \mu \mathrm{G}$ TRH OR SALINE WITHIN IMIPRAMINE AND PLACEBO GROUPS PRE- AND POST-TREATMENT

\begin{tabular}{ccccccccc}
\hline \multirow{2}{*}{$\begin{array}{l}\text { Number of } \\
\text { side effects } \\
\text { experienced }\end{array}$} & $\begin{array}{c}\text { Pre-Treatment } \\
\text { Saline }\end{array}$ & TRH & Post-Treatment & \multicolumn{4}{c}{ IMIPRAMINE } \\
Saline & TRH & Saline & TRH & Saline & TRH \\
\hline 0 & 3 & 0 & 4 & 0 & 5 & 2 & 5 & 0 \\
1 & 1 & 0 & 1 & 1 & 0 & 0 & 1 & 4 \\
2 & 1 & 3 & 0 & 2 & 2 & 1 & 1 & 1 \\
3 & 0 & 1 & 0 & 0 & 0 & 0 & 0 & 0 \\
4 & 0 & 0 & 0 & 0 & 0 & 3 & 0 & 1 \\
5 & 0 & 0 & 0 & 1 & 0 & 1 & 0 & 1 \\
6 & 0 & 0 & 0 & 0 & 0 & 0 & 0 & 0 \\
7 & 0 & 1 & 0 & 1 & 0 & 0 & 0 & 0 \\
\hline
\end{tabular}

${ }^{a} p<0.05,{ }^{b} p<0.04,{ }^{c} p<0.03$, saline vs. TRH.

toward a greater urinary urgency response to TRH after treatment, yet the only significantly elevated response occurred within the IMI group at $30 \mathrm{sec}$ after injection.

TCA plasma levels were: IMI, $35.1 \pm 12.0 \mathrm{ng} / \mathrm{ml}$; desipramine, $48.0 \pm 25.3 \mathrm{ng} / \mathrm{ml}$; total IMI + desipramine $83.0 \pm 30.9$. Table II summarizes the other responses experienced by the subjects. Although subjects within both groups experienced an increase in all areas examined, only nausea proved to be significantly more prominent, except in the IMI post-treatment group, which tended toward significance. The frequency of side-effects experienced per condition per number of subjects are shown in Table III. 


\section{DISCUSSION}

IMI failed to alter the urinary urgency response to TRH. The urinary urgency responses to TRH were significantly greater than to saline in the pre- and post-treatment conditions for both groups. The duration of urinary urgency experienced by our subjects parallels those previously noted (Bhatia \& Bergman, 1988): In this study, urinary urgency was noted for 5-10 min after an infusion of $500 \mu \mathrm{g}$ TRH. This appears to conflict with an earlier report of urinary urgency lasting from a few to several seconds (Nathan, 1983). Unfortunately, the methodology by which the observations of that study were made was not specified, leaving one to assume that these were either based on clinical observations or ancillary retrospective observations.

The therapeutic action of IMI in children with enuresis is most likely not mediated by the blockade of TRH-induced urinary urgency. The consistency of the TSH responses strongly supports the lack of an alteration of the HPT axis in response to IMI. Several possible factors exist that may have played a role in the inability of IMI to alter the urinary urgency response. First, the dose of IMI may have been insufficient. This dose was chosen because it has been shown to be effective in the treatment of enuresis. Whether a higher dose might be effective, especially in healthy adults, is unknown. Second, the time period of testing may not have been optimal. This time period was chosen based on earlier studies indicating that a child's responses to IMI would occur within 10 days. Third, a study of 12 normal healthy adults may neither approximate nor parallel the psychophysiology found in childhood enuresis.

Our data do not support a major interaction between TRH and the urinary tract which is influenced significantly by the pharmacological action of IMI. This would suggest that the therapeutic action of IMI in children with enuresis is most likely not mediated via TRH, at least with respect to those symptoms that are most related to urgency and frequency. Any final conclusions would have to be drawn from a study involving children with enuresis, given that our results were derived from normal healthy men.

\section{REFERENCES}

Bhatia NN, Bergman A (1988) Urinary urgency following administration of thyrotropin releasing hormone during simultaneous urethrocystometry. Urology 31: 180-183.

Bindeglas PM, Dee GH, Enos FA (1968) Medical and psychosocial factors in enuretic children treated with imipramine hydrochloride. Am J Psychiatry 124: 1107-1112.

Esperanca M, Gerrard JW (1969) Nocturnal enuresis: comparison of the effect of imipramine and dietary restriction on bladder capacity. Can Med Ass J 101: 721-724.

Hagglund TB, Parkkulainen KV (1965) Enuretic children treated with imipramine: a cystometric study. Ann Paediat Fenn 11: 53-59.

Hallgren B (1956) Enuresis I. A study with reference to the morbidity risk and symptomatology. Acta Psychiatr Neurol Scand 31: 379.

Johnson SM, Chan C, Cheng S, Shimek JL, Nygard G, and Wahba Khalil SK (1982) Isocratic highperformance liquid chromatographic method for the determination of tricyclic antidepressants and metabolites in plasma. J Pharmaceut Sci 71: 1027-1030.

Jorgensen OS, Lober M, Christiensen J, Gram LF (1980) Plasma concentration and clinical effect of imipramine treatment of childhood enuresis. Clin Pharmakokin 5: 386-393.

Mikkelsen EJ, Rapoport JL \& Nee L, Gruenau C, Mendelson W, Gillin JC (1980) Childhood enuresis I. Sleep patterns and psychopathology. Arch Gen Psychiatry 37: 1139-1145.

Nathan RS (1983) Urinary urgency induced by thyrotropin releasing hormone. Psychiatry Res 8: 153-154.

Rapoport JL, Mikkelsen EJ, Zavardil A, Nee L, Gruenau C, Mendelson W, Gillin JC (1980) Childhood enuresis II. Psychopathology, tricyclic concentration in plasma, and anti-enuretic effect. Arch Gen Psychiatry 37: $1146-1152$. 
Shaffer D (1985) Enuresis. In: Rutter M, Hersov L (Ed) Child and Adolescent Psychiatry, Modern Approaches. Blackwell Scientific Publications, Oxford, pp 465-481.

Shaffer D, Costello, AJ, Hill JD (1968) Control of enuresis with imipramine. Arch Dis Child 43: 665-671.

Shaffer D, Hedge B, Stephenson JD (1978) Trial of an alpha-adrenolytic (Indoramin) for nocturnal enuresis. Dev Med Child Neurol 20: 183-188.

Spitzer RL, Endicott J (1975) Schedule for Affective Disorders and Schizophrenia - Life Time Version, Second Edition. New York State Psychiatric Institute.

Starfield B, Mellits ED (1968) Increase in functional bladder capacity and improvements in enuresis. $J$ Pediatr 72: $483-487$.

Torrens MJ, Collins CD (1975) The urodynamic assessment of adult enuresis. Br J Urol 47: 433-439.

Vaidyanathan S, Rao MS, Sharma PL, Sachdeva NK (1983) Modulation of urinary bladder function with TRH in patients with spinal cord injuries during the spinal shock phase. Ann Clin Res 15: 66-70.

Wallace IR, Forsythe WI (1969) The treatment of enuresis: a controlled clinical trial of propoantheline, propantheline and phenobarbitone, and placebo. Br J Clin Prac 23: 207-210. 